\title{
Crisis thinking, sensuous reflexivity, and solving real issues
}

\author{
Jürgen Jaspers
}

Université Libre de Bruxelles (ULB)

The founding modernist move, Richard Bauman and Charles Briggs write in Voices of Modernity, their grand overview of the birth and maturation of modernity, is to "posi[t $\mathrm{t}$ a category of tradition, mak[e] it seem autonomous, and then creating new hybrids that contain tradition by virtue of being defined in opposition to it" (2003:307). Rather than the summary term for an array of historical changes (the onset of capitalism, secularisation, industrialism, and so on), these authors understand modernity as a discursive construction that opposes traditional and modern developments, ways of being, and modes of understanding. Central in this narrative project have been conceptions of language. A first step involved John Locke's imagination of language as a separate, autonomous domain of human intervention, standing apart from nature and from the social world. The second step was his argument that language needed to be purified so that its use could be trusted in these two other domains. In order to make it a tool for the accurate exchange of empirical knowledge, and less dangerously prone to misunderstanding in the political sphere, language needed to be stripped from ambivalence, intertextuality, connotation and emotion - all of them qualities an elite of urban, cosmopolitan gentlemen attributed to the speech of those they found ignorant, superstitious, lower class, indigenous, rural, in sum, premodern. And because purification required education, it was only logical to "claim[...] consciousness and rationality for oneself and one's followers and deny[...] it to others" (Bauman \& Briggs 2003:298) - a move Fabian (1983) earlier called the "denial of coevalness".

This logic of temporalisation has been so fundamental, Bauman and Briggs hold, that it was deeply embedded too in the work of later authors like Johann Gottfried von Herder and Franz Boas, although they take up diametrically opposed positions - from Locke, and from each other - in their understanding of the local vs. global, rationality vs. emotion, deficit vs. difference, or individual autonomy vs. community custom. Bauman and Briggs argue moreover that this logic continues to impinge on contemporary visions of large-scale social change:

AILA Review 29 (2016), 199-213. DOI 10.1075/aila.29.08jas 
Tradition, which has been reportedly on the verge of dying for more than three centuries, [...] continues to provide useful means of producing and legitimizing new modernist projects, sets of legislators, and schemes of social inequality

(2003:306)

Such comebacks of tradition are in particular said to transpire in the writings of scholars who critically evaluate modernity, like Zygmunt Bauman (1987), Giddens (1994), and Beck (1994). Setting aside their mutual differences, each of these authors, in imagining liquid, high or late modernity, has tended to invoke a more traditional way of life that invariably involves a more stable, relatively small setting where representations are shared and/or transparant. This vision of the 'simple' life is then opposed to the complexity, instability, enormity or acute reflexivity of the current era (cf. Bauman \& Briggs 2003:306-307). In these visions of change, in other words, modernity becomes the new tradition, while late-modern reflexivity replaces modern rationality as the pinnacle of human autonomy. Echoes of this logic may also be present in sociolinguistic evocations of the traditional, stable, or homogeneous speech community, real or imagined, and its opposition to linguistic practices in current, more complex, aggregates of people that only a new sociolinguistics is capable of explaining. Yet, as Bauman \& Briggs warn:

any claim to deconstruct or get beyond modernity that invokes these sorts of constructions of tradition is bound to fail in that it infiltrates a founding modernist move into its own rhetorical, epistemological, and political foundations.

(2003:307)

Insights such as these call for caution when authors propose that "for the first time in human history, the reflexive imperative is becoming categorical for all, although manifesting itself in only the most developed parts of the world" (Archer 2012: 1), or that "the individual is becoming the basic unit of social reproduction for the first time in history" (Beck \& Beck-Gernsheim 2002: xxii; quoted from Dawson 2010: 191). That such proclamations may be more revealing of the modernist ambition to mark a new age than of genuine social change is also argued by Robert Moore, an educational sociologist, who refers to literary critic Frank Kermode's 1965 lectures (reprinted in 2000) on apocalyptic myths and their secular translation into art and literature. Moore refers in particular to Kermode's discussion of the 'myth of modern transitionalism':

It is commonplace that our times do in fact suffer a more rapid rate of change technologically, and consequently in the increase of social mobility, than any before us. There is nothing fictive about that, and its implications are clear in our own day to day lives. What is interesting, though, is the way in which this knowledge is related to apocalypse, so that a mere celebratory figure for social mobility, like On the Road, acquires apocalyptic overtones and establishes the 
language of an elect; and the way in which writers, that is to say, clerks, are willing to go along, arguing that the rate of change implies revolution or schism, and that this is a perpetual requirement; that the stage of transition, like the whole of time in an earlier revolution, has become endless. This is the modern apotheosis of joachism: the belief that one's own age is transitional between two major periods turns into a belief that the transition itself becomes an age, a saeculum [...] Crisis is a way of thinking about one's moment, and not inherent in the moment itself.

(Kermode 2000: 101; quoted from Moore 2007:41)

The point to be made here is two-fold. First, this quote already hints at the kind of rapid changes, albeit only technological ones, that we customarily associate with globalisation but which Kermode found commonplace in 1965. Kermode contends however, secondly, that these changes are actively recruited to postulate the special, radically new character of the then contemporary era and that this recruitment strategy, rather than the changes themselves "is as endemic to what we call modernism as utopianism is to political revolution" (2000:98). We have a penchant for crisis thinking, in other words, and for finding

our own crisis [...] pre-eminent, more worrying, more interesting than other crises [...] It is commonplace to talk about our historical situation as uniquely terrible and in a way privileged, a cardinal point of time. But can it really be so? It seems doubtful that our crisis, our relation to the future and the past, is one of the important differences between us and our predecessors. Many of them felt as we do. If the evidence looks good to us, so it did to them. (Kermode 2000:94-95)

Though not mentioned by Kermode, these words tie in with Karl Löwith's secularisation thesis of modernity (1949), which posits that modernity as a 'secular faith' remains profoundly indebted to an eschatological view of history. ${ }^{1}$

We may be using different images to visualise a sense of ending - no armies in the sky anymore, nor even nuclear bombs perhaps, but 'mass migration', 'linguistic destandardisation', or 'complexity', to name only a few, all work to conjure up the idea of momentous change that legitimises intervention and authorises crisis thinkers. Less addressed by Kermode is that endings are not just fearsome but also, as Kompridis (2006) suggests, seductively new. They harbour the promise of something new, something better. Fascinated by future possibilities, the present so becomes a site of constant collision between the suspected old and the auspicious new. Kompridis further suggests that:

1. Though, as McKnight (1990) argues, Löwith's thesis overlooks the contribution of magic, alchemy, and esoteric religion to ideas of human fulfillment and of a God-like domination of nature that transcends medieval ignorance or error. 
the experience of the present as a time of crisis is not only due to modernity's openness to the novelty of the future; it is also due to the way in which the future functions as a source of pressure brought to bear on currently unsolved problems, on available but unnoticed or unexploited possibilities [...] we are the ones who must self-consciously renew and correct our forms of life, who must repair what is broken, or break with what seems irreparable. We are the ones who must remake our languages and practices, and make something new out of something old.

(Kompridis 2006: 15; emphasis in original)

Acutely aware of the potential new beginnings that we could facilitate the birth of, we come under the influence of a sense of urgency towards a future that will look upon the present as a new past. Locke's ideas and propositions to purify language, but also much work in applied and sociolinguistics that sets out to solve 'real' problems surely testifies to this sense of pressure. Apart from introducing genuine change, intended or not, it frequently stirs up resentment against people's continuing investment in traditional, for example, monolingual ideologies, or against linguists' interest in 'unreal' issues.

Postulations of a new age, Moore continues, also "have a paradigmatic quality as a distinctive type of intellectual episode" (2007:40) because they often invite schismatic discourse. Typical for such discourse "is its claim to orginality - it is being thought for the first time" (2007:44). The drift of this thinking is anti-canonical: "it works to delegitimize, or debunk, the authority of an established body of knowledge and its presumed representatives" (2007:44). And in being focused on deconstructing, schismatic discourse often translates into a proliferation of "approach paradigms" (2007:45; quoted from Bernstein 1977: 157) and classifications of scientists on either side of the divide. The argument here, of course, is not that incisive criticism of existing representations and approaches is wrong, but that the logic of schism gravitates towards accentuating difference, temporalising others, and sanctifying new authorities. Again, it would be difficult to ignore at least some parallels between these issues and applied linguistic work that - against "traditional understandings of education" and enabling us to "transgress the categorical distinctions of the past" (García \& Li Wei 2014:2) - adamantly proposes 'translanguaging' as much better attuned to the fact that we have now "entered [...] new ways of being in the world" (2014:9). I say this not to discredit the linguistic or pedagogic practices thus named, nor to question the idea of intervention or renewal. It is to indicate that these practices are recruited to make epochal claims, are proposed as almost uniquely compatible with - or 'natural' in - a globalised world, and are often seen to be unequivocally positive, if not liberating, forces. Each of these moves is questionable, though, not to mention that all (language) learning, in principle, is a process of 'entering a new way of being in the world', regardless of its trans- or monolingual character. 


\section{The reflexive imperative}

Archer's postulation of the 'reflexive imperative' likewise seems to rehearse classic modernist and paradigmatic moves. This is not per se related to her emphasis on the importance of reflexivity for explaining social action. To be sure, and as is duly noted by Archer herself (2012:2-3), the notion of reflexivity as a fundamental aspect of the construction of society has a venerable pedigree in sociology. Authors such as Giddens (1984), Garfinkel (1967) and before that Parsons (1937) have insisted that any explanation for society must eventually confront people's capacity for acting on the basis of their own decisions and aspirations if one wishes to avoid accounts that invoke the determining constraints imposed by the economy, the body, spiritual ideals or cultural essences. Dissatisfied with Parsons' eventual reduction of reflexivity to scientific rationality, Garfinkel argued that reflexivity is generic in all social activity because people's approximate, common-sense and verbalised judgements are prerequisite for establishing mutual knowledge, accounting for one's behaviour, and orienting to meaningful courses of action. In this sense, Giddens argued, "the production of society is a skilled performance [...] only made possible because every (competent) member of society is a practical social theorist; in sustaining any sort of encounter he [or she] draws upon his [or her] knowledge and theories, normally in an unforced and routine way, and the use of these practical resources is precisely the condition of the production of the encounter at all" (1976: 15-16). Reflexivity so emerges as an ontological imperative, aptly summarised by Archer as "no reflexivity, no society" (2012:2).

Archer falls into the modernist trap however when she consequently suggests that her own, extended, notion of reflexivity - people's capacity for observing themselves in relation to their surroundings - is a necessary response to the present, radically "novel" circumstances, where "habits and habitus are no longer reliable guides" (2012: 1). Taking up 'habits' in this quote first, Archer implies that in a world characterised by intense mobility, long education trajectories and cultural diversity, social origins fail to provide individuals with the know-how for acting competently and effectively. Reflexive deliberation, defined as a type of internal dialogue or "self-talk" (2012:14), becomes the only anchor that holds in the social storms. The question of how radically new these circumstances are, however, appears to be less high on Archer's empirical agenda (Caetano 2014), inviting the charge of transitionalism. Naturally there are social changes that it is worthwhile attending to. The authors in this issue for example address specific population changes in Western-Europe (Lehtonen 2016; Patiño-Santos 2016), the neo-liberalisation of education (Pérez-Milans \& Soto 2016; Lu 2016; De Costa et al. 2016), the spread and impact of social media (Pérez-Milans \& Soto 2016), or nation-states' responses to the increasing value of multilingualism and transnational mobility 
(Lu 2016; Van Lancker 2016). In addition to this, Archer as well as the authors in this issue are duly sensitive to an intense (self-)reflexivity that is encouraged by communication technologies and the omnipresence of (mass) media, valued as a particular communicative and commodifiable skill, and perhaps generally treated as a sign of intelligence and emotional health (cf. Carr 2006).

The question remains however if these evolutions are so radically new that 'habits' - social dispositions acquired through socialisation - now fail to have much impact, or have disappeared to culminate in a state of perennial uncertainty. In trying to make sense of social change, as Bourdieu warned, it is important to avoid the twin traps of ignoring the continuities and overlooking the discontinuities. Given that each time-space configuration displays an impure mix of change (however temporary) and continuity, it is therefore expedient, when it comes to appreciating the impact of habits on social action, to "resist the long-standing appeal of one or the other of these two extremes: thinking of ourselves either as standing completely outside of our traditions, in no way affected by or indebted to them, or, as identical with our traditions, fatefully bound to or enclosed within them" (Kompridis 2006:7). Empirically speaking, all papers in this issue are testament to the fact that social origins continue to affect individuals' agency without over-determining these individuals' negotiation of their structural conditions.

Lehtonen's (2016) discussion of 'stylised bad Finnish' for example shows the continuing vulnerability of diasporic language learning trajectories in relation to long-standing categories of 'good', that is, unmixed and white, Finnish. But she also reveals speakers' capacity for distancing themselves from these long-standing identity slots through mockery, "reclaiming the pejorative language that has been used to and about them" and in this way "drawing its sting" (Coupland 2003: 20; cf. also Jaspers 2011b; Talmy 2009). De Costa et al. (2016) demonstrate how a similar negative confrontation with long-standing fluency ideals is resisted (though also sorely resented) by a student through gradual reclusion, facilitated, or softened, by his material affluence. Pérez-Milans \& Soto (2016) insist on the importance of networks for understanding an individuals' upward trajectory in a starkly stratified education system by means of socialisation into a widely recognised and valued discursive register (viz., that of being/doing a minority activist). Lu (2016) in addition shows how personal concerns and ways of acting among elite students in Singapore are distinctly commensurate with their privileged background and educational trajectory, contra Archer's view of the diminishing relevance of such backgrounds. The imprint of this background transpires, Lu argues, in the fact that those who have to, or wish to, diverge from the expected pattern accountably justify their decision or report being held to account. Similar self-reflexive justifications can be found in Patiño-Santos's (2016) analysis, though here, the analysis 
establishes a conflict between different habitualised concerns, viz., between articulated ones (where girls revoice the importance of study, construct themselves as moral authorities, orient to being the family's pride) and embodied ones (in which these same girls are revealed as consumed by the social dimensions of school, and as leaving school for inscribing themselves in longer-standing, shared narratives of motherhood and low-educated jobs). Van Lancker (2016) in her case nicely teases out how privileged pupils' articulated image of linguistic tolerance jars with their embodied disposition, in line with their background and expected future status, that values the school-promoted Standard Dutch.

This demonstration of the continuing impact of social origins is in tune with various authors' insistence on the durability of prematurely declared 'zombie' categories (cf. Beck \& Beck-Gernsheim 2002) like class, gender, or sexuality (cf. Block 2014; Dawson 2010; Marsh 2011; Moore 2007; Rampton 2006; Reay 2006; Skeggs 2004). This also holds for the notion of separate languages (cf. Jaspers \& Madsen 2016): in spite of sociolinguists' ample attempts to highlight its ideological nature, various papers in this issue illustrate that the idea of separate, pure, standard language continues to play a vital role, either as something to invest in and climb the social ladder with, or as a tool with which to distinguish oneself from others (Lehtonen 2016; Pérez-Milans 2016; Van Lancker 2016).

Admittedly, the continuing impact of these social origins could be explained within Archer's theory itself, in particular as symptomatic of participants' communicative type of reflexivity. This is a type of internal conversation in which individuals still remain dependent on outside confirmation of their thoughts before launching into action. Archer (2012: 12ff.) distinguishes this type from an independent, 'autonomous' reflexivity which, in opposition to the former type, consists of inner dialogues that lead to direct action, regardless of co-participants' approval. She subsequently identifies a 'meta-' and 'fractured' type of reflexivity which result from, respectively, revising one's previous internal conversations on the basis of new information, and from experiencing personal distress and disorientation when individuals feel unable to pursue their personal concerns. While in principle "we all do resort to each of the four modes of internal conversation on different occasions and in different situations" (Archer 2012:12), it soon transpires however that communicative reflexivity is Archer's premodern type: "early societies, in which structure and culture [...] contributed to the restoration and perpetuation of the status quo, were also the ones likely to have fostered communicative reflexivity amongst the large majority of the population" (Archer 2012: 18). Autonomous reflexivity in this view thus emerges as a purer, more sophisticated reflexivity. Meting out different types of reflexivity to their alleged owners logically facilitates their potential placement in unequal, temporally different, positions. 


\section{A sensuous reflexivity}

The mention of 'habitus' in Archer's quote above ('habits and habitus are no longer reliable guides') indicates that she opposes herself to dispositionalist theories, such as Bourdieu's or Giddens's, which invoke a type of habitualisation to explain recurrent social structure. Archer instead proposes a 'morphogenetic' approach (Archer 1995). This approach sets out to avoid 'conflationist' theorising, that is, explanations according to which social action is principally driven by either agency or structure. Finding that Bourdieu's habitus concept denies causal autonomy to agency, ${ }^{2}$ Archer agrees with Giddens's view that agency and structure are co-constitutive, and thus conceptually inseparable, on philosophical grounds. Yet she analytically objects to it as a 'conflationist' approach because it hinders the empirical analysis of their interdependence. Because structure and agency run on different timescales, Archer argues, they need to be studied as morphogenetic sequences, that is, as a succession of events where structure each time provides an antecedent context, exerting a more or less constraining impact on agentive action, within which agents can then produce action (driven by their internal dialogue) which feeds back into the original context and potentially transforms it. All in all, this is not so different from Agha's assertion that "cultural formations are reproduced over social groups through communicative processes that unfold one participation framework at a time" (2007:9). But the similarity is superficial.

To be sure, in order to keep away from any 'conflationism', it becomes crucial in Archer's theory to conceptualise action as driven exclusively by internal dialogue vis-à-vis the conditions that constrain individuals to pursue their personal concerns. Doing so, however, not only ignores the importance of external conversation as a mediator between agentive action and structural constraints (cf. also Caetano 2014: 8). It also implies that action in this morphogenetic perspective acquires a pristine, uncontaminated character, seeing as it is merely "constrained by cultural conventions/structures externally" (Pérez-Milans 2016, my emphasis). Stripped of any historical débris the recognition of which as a causal factor would raise the spectre of conflationism, the pursuit of concerns in this perspective risks becoming a radically ad hoc affair. This pursuit must in addition be carried out by

2. This is a contentious point. Bourdieu argues that "the habitus is an endless capacity to engender products - thoughts, perceptions, expressions, actions - whose limits are set by the historically and socially situated conditions of its productions, the conditioned freedom it secures is as remote from creation of unpredictable novelty as it is from a simple mechanical reproduction of the initial conditionings." (Bourdieu 1977:95) Yet how, exactly, the resulting agency causes exceptional social action that diverges from the dominant trends of reproduction Bourdieu draws attention to is usually less well developed (cf. Moore 2007: ch. 4). 
a maximally conscious actor given that unconscious, routine ways of acting again hybridise the purified self-deliberation. Such a perspective, in line with Archer's characterisation of Garfinkel and Giddens's insights above, could perhaps be summarised as 'reflexivity without society', or as maintaining what Fabian (1983) would call a 'disembodied consciousness'.

In contrast to such a view, and as part of his reconsideration of the production of all kinds of knowledge (ethnographic and otherwise), Fabian argues for a materialist conception of knowledge within which language plays a crucial role:

A first and foremost assumption of a materalist theory of knowledge [...] is to make consciousness, individual and collective, the starting point. Not disembodied consciousness, however, but "consciousness with a body", inextricably bound up with language. A fundamental role for language must be postulated, not because consciousness is conceived as a state internal to an individual organism which would then need to be "expressed" or "represented" through language [...] Rather, the only way to think of consciousness without separating it from the organism or banning it to some kind of forum internum is to insist on its sensuous nature; and one way to conceive of that sensuous nature [...] is to tie consciousness as an activity to the production of meaningful sound.

(Fabian 1983: 161)

A similar sensuous consciousness is advocated by Agha when he points out that "any [...] [sign] [...] must be conveyed by a perceivable thing - i.e., be materially embodied - in order to become known to someone, or communicable to another" (2007: 2). Viewing communication as intrinsically semiotic and embodied, however, has far-reaching repercussions. It entails that awareness is conditioned by, rather than precedes, the production of material signs (sounds, pixels, ink) that people recognise as connecting themselves with each-other (whether face-to-face, at long distance, or with an imaginary conversation partner). What further troubles the waters of pristine self-deliberation on a 'forum internum' is that the production of signs unavoidably depends on socialisation (through which individuals learn to recognise signs as having particular meanings) and histories of usage (in which people have typified signs as having such meanings) (cf. Agha 2007:12) - not to mention the necessity of socialisation and usage histories for producing linguistic signs in a phonologically and syntactically recognisable way. Quite the opposite from Archer's motto above, this view could be termed 'no society, no reflexivity'.

Language ceases to be "innocent, socially disconnected behaviour" (Coupland \& Jaworski 2004: 16) in this view, because it comes 'loaded' with, or is indexical of, earlier usages, and with different if not competing typification habits (cf. Bakthin 1981). It is this loadedness that provides for its capacity to evoke or entail co-occuring signs, as well as contexts and relationships in which they are seen to occur by language users (cf. Silverstein 1993). Even though recognising what signs are indexical, and socially indexical, of is in principle ad hoc 'completion work' 
(Jaspers 2011a), even for merely denotational use, this completion labour relies on shared common-sense 'methods' (cf. Garfinkel 1967) that people socialise each other into bringing to bear so as to make sense of themselves, their relation and their environment.

So, in failing to take account of the historicity, materialism and collective sharedness of the semiotic signs that people must recruit to make sense of and account for themselves in relation to others and to meaningful courses of action, and in overlooking the conventions and socialisation that this sense-making relies on, Archer's theory of how people negotiate their daily circumstances would seem to miss a crucial point.

\section{Solving real issues}

It would be easy at this stage to traditionalise Archer's theory as less developed in comparison to modern socio- or applied linguistic insights, and to make our own priority everybody else's through suggesting that such insights must be henceforth lie at the basis of any further explanation of social action. This would be an effective claim to academic legislatorship (cf. Bauman \& Briggs 2003:309). As the papers in this issue exemplify, it may be more useful to explore how these insights can address Archer's own questions and deepen the answer. Such an exploration has not, however, immediately led to practical answers or to an outline for solving 'real' issues. This is despite the various efforts across the papers to indicate 'specific implications' for applied researchers and practitioners (which mostly sketch the potential relevance for practitioners with an interest in reflexivity, or offer counter-evidence for policymakers' contentions). This may be illustrative of a longer-standing challenge for the field of applied linguistics, where 'intellectual' (as in this issue) and 'practical' pursuits orient to different and increasing institutional demands (cf. Kramsch 2015). It may be symptomatic too of a tension that characterises university research in general, where "the imperative to pursue the fuller understanding of any subject-matter once it was established as part of an academic discipline constantly tend[s] to exceed and subvert the imperative to meet immediate or local needs" (Collini 2012: 26), however applied a particular scientific branch starts out.

That said, the accounts offered in this issue of young people's "discursive laminations of past, present and future" (Pérez-Milans 2016) do provide a "lens [...] [that] shapes what it is possible to see and understand about a particular phenomenon" (Lillis 2015:2). They draw attention to the fact that youth across the globe are neither 'standing completely outside of their (linguistic, socio-economic, gender, regional or ethnic) tradition', neither can they be seen as 'identical with 
these traditions, fatefully bound to or enclosed within them' (cf. Kompridis 2006). Indeed, their discursive laminations go to show that their individual negotiation of longer-standing and/or predominant constraints and discourses, whether this involves self-talk or not is, firstly, a networked activity - rubbing against deeply entrenched (Western) discourses of individual self-interestedness and self-sufficiency; and, secondly, that this negotiation is an ambiguous, messy affair in the sense that it depends on deploying habitually used, collectively recognised, historically molded, material signs in new contexts that may affect other contexts of use as a result of this.

This combination of both recycling and renewing, altering and maintaining, also transpires in how these youth 'solve' the different real issues (views, positions, expectations, discourses, problems) in their own lives. The stylisations in Lehtonen (2016) and Van Lancker (2016) alluringly mock, but simultaneously re-associate disfluent Finnish and Standard Dutch respectively with low and high status. Confronted with a moral discourse that emphasizes individual commitment at school, the girls described by Patiño-Santos (2016) construct narratives of moral authority (albeit in non-schoolish matters) which eventually conflict with the moral duty to keep their promise, boosting the very discourse of self-discipline they were confronting. The studious youth in Lu's (2016) paper who escape poor prospects through competitive learning in effect reinforce those poor prospects for other, less competitive youth. Pérez-Milans \& Soto's (2016) description of one individual's successful ascendance on the social/educational ladder equally demonstrates how this was facilitated by an investment in English, bolstering the value of monolingualism; Sita's success at the same time reproduced the value of educational distinction. Rather than evoking these outcomes to suggest that solving problems does more harm than good, this is to emphasise that individual solutions will inevitably be inflected by, and often reproduce, the wider-scale structures in which they are acted out. Just like there is no pristine forum internum whence to ponder over next steps to be taken, then, these steps themselves, whether practically or scientifically legitimised, will never be neat or simple. Proposing interventions without losing sight of what is reproduced in the process will be a continuous challenge for applied linguistics.

The relatively low level of applicability offered by these papers ought not to be taken as a sign of their lack of attention to real world issues, though. If there is one that runs through almost all papers, it is (people's expectations of, success in, or lack of) social mobility. This is a concern shared with a great deal of applied and sociolinguistic research, and it chimes in with the consensus view that reforming and democratising education will redefine social opportunities (cf. Moore 2007). In concluding I suggest that this concern with social mobility highlights a particular quality of the issue, but itself also raises concerns that applied (and socio-) linguistics as a field may have to address. 
While there is a growing interest in those coming from more privileged backgrounds (cf. Bucholtz 2011; Cutler 1999; also see Reay et al. 2007), much research (my own included $)^{3}$ has tended to prioritise less privileged youth, or those youth seen to perform less well at school, with a view to either boosting their reputation (as different or dominated, rather than deficient) and/or their social mobility (by enhancing their learning, or changing negative attitudes towards them). This preoccupation has often helped to reinforce the problematic identity of working class youth, however, through invoking the supposed normality of those who were not seen to be in need of any help, that is, middle and upper class youth. It is a quality of this issue, therefore, that it makes room for a discussion of privileged and non-privileged students. While less pronounced in Van Lancker's (2016) paper, $\mathrm{Lu}$ (2016) and De Costa et al. (2016) exemplify the type of anxieties and pressure that those who seemingly have nothing to worry about struggle with, showing that "the middle classes' intense and increasingly anxious preoccupation with educational achievement can be as damaging as working-class underachievement" (Reay 2010:399; also see Hambye \& Siroux 2008, for an example of investigating language use among elite and non-elite youth).

The focus on social mobility in this issue must be applauded from a perspective that problematises social inequality. Yet it must be underlined too that deploring the absence of such mobility as an "unhappy ending" (cf. Patiño-Santos 2016) and seeking to find out how non-privileged students can swim against the educational current in principle accepts inequality as something that individuals must escape (for example, through long-term study), and idealises middle- or upper-class identity as an aspiration for others (cf. Reay et al. 2008). Applied and sociolinguistics will eventually have to come to terms as well with the insight that, as a number of sociologists have been arguing, educational policy has had relatively little or no influence on social mobility beyond school walls (Freeman-Moir \& Scott 2003; Moore 2007; Reay 2010; also see Marsh 2011). This is in spite of the widely shared conviction, among policy makers, pedagogues and linguists, that introducing the right type of language (pedagogy) at school will generate educational success and lay the foundation for later social mobility (cf. Jaspers 2017). Indeed, "[t]he irony is that the rhetoric of social mobility and equal opportunities within education has increased in volume and intensity as both have become less possible in practice" (Reay 2010:399). This is a sobering realisation. It does not invalidate educational reform per se, however. As Moore (2007) argues, such reforms may certainly reduce inequality within schools. What must be seriously questioned though, is the idea that schools have a direct impact on social opportunities, inequality or

3. I am, for the sake of the argument, ignoring the field of foreign language acquisition research, where attention to adults from relatively privileged backgrounds is nothing special. 
the economy outside of the school, and vice versa. This is not to deny any impact, but to insist that positions in one field will always be negotiated and transformed in the other, without guarantees of duplication. Relations between the school and the outside world must thus be seen as contingent rather than isomorphic (Moore 2007). Such a view certainly offers new opportunities. If schools do not simply motor social mobility, the reduction of inequality may be more effectively pursued through focusing on it directly, rather than indirectly through the school or through discourses that represent social mobility as the outcome of individual discipline, equal opportunities and responsible choosing. But it also presents challenges to disciplines which have tended to inscribe themselves in the logic of faster, higher, stronger learning in view of its impact on social inequality. What could applied linguistics offer to schools where learning isn't principally linked to particular social destinations, but focused on transforming individuals in ways that we think are morally desirable? Can it contribute to an education that isn't in the first place focused on individual excellence but on collectively making sense of, maintaining and renewing society through knowledge of language?

\section{References}

Agha, A. 2007. Language and Social Relations. Cambridge: CUP.

Archer, M. 2012. The Reflexive Imperative in Late Modernity. Cambridge: CUP. doi:10.1017/CBO9781139108058

Bakhtin, M. 1981. The Dialogic Imagination: Four Essays, C. Emerson \& M. Holquist (trans, ed.). Austin TX: University of Texas Press.

Bauman, R. \& Briggs, C. 2003. Voices of Modernity. Language Ideologies and the Politics of Inequality. Cambridge: CUP. doi:10.1017/CBO9780511486647

Bauman, Z. 1987. Legislators and Interpreters. Ithaca CA: Cornell University Press.

Beck, U. 1994. The reinvention of politics. Towards a theory of reflexive modernization. In Reflexive Modernization: Politics, Tradition and Aesthetics in the Modern Social Order, U. Beck, A. Giddens \& S. Lash (eds), 1-55. Palo Alto CA: Stanford University Press.

Beck, U. \& Beck-Gernsheim, E. 2002. Individualization. London: Sage.

Bernstein, B. 1977. Towards a Theory of Educational Transmission. Class, Codes and Control, Vol. 3, 2nd edn. London: Routledge \& Kegan Paul.

Block, D. 2014. Social Class in Applied Linguistics. London: Routledge.

Bucholtz, M. 2011. White Kids. Language, Race and Styles of Youth Identity. Cambridge: CUP. Caetano, A. 2014. Defining personal reflexivity. A critical reading of Archer's approach. European Journal of Social Theory 18 (1): 60-75. doi:10.1177/1368431014549684

Carr, E.S. 2006. 'Secrets keep you sick': Metalinguistic labor in a drug treatment program for homeless women. Language in Society 35 (5): 631-653. doi:10.1017/So047404506060301 Collini, S. 2012. What are Universities for? London: Penguin Books.

Coupland, N. 2003. 'Other' representation. In Handbook of Pragmatics, J. Verschueren, J.-O. Östman, J. Blommaert \& C. Bulcaen (eds). Amsterdam: John Benjamins. 
Coupland, N. \& Jaworski, A. 2004. Sociolinguistic perspectives on metalanguage: Reflexivity, evaluation and ideology. In Metalanguage: Social and Ideological Perspectives, A. Jaworski, N. Coupland \& D. Galasinski (eds), 15-51. Berlin: Mouton de Gruyter. doi: $10.1515 / 9783110907377.15$

Cutler, C. 1999. Yorkville crossing. White teens, hip hop and African American English. Journal of Sociolinguistics 3 (4): 428-442. doi:10.1111/1467-9481.00089

Dawson, M. 2010. Bauman, Beck, Giddens and our understanding of politics in late modernity. Journal of Power 3 (2): 189-207. doi:10.1080/17540291.2010.493698

De Costa, P., Tigchelaar, M. \& Cui, Y. 2016. Reflexivity and transnational habitus: The case of a 'poor' affluent Chinese international student. AILA Review 29(1).

Fabian, J. 1983. Time and the Other. How Anthropology Makes its Object. New York NY: Columbia University Press.

Freeman-Moir, J. \& Scott, A. 2003. Yesterday's Dreams. Christchurch NZ: Canterbury University Press.

García, O. \& Wei, L. 2014. Translanguaging. Language, Bilingualism and Education. London: Palgrave Macmillan.

Garfinkel, H. 1967. Studies in Ethnomethodology. Englewood Cliffs NJ: Prentice Hall.

Giddens, A. 1976. New Rules of Sociological Method: A Positive Critique of Interpretative Sociologies. London: Hutchinson.

Giddens, A. 1984. The Constitution of Society. Outline of the Theory of Structuration. Cambridge: Polity Press.

Giddens, A. 1994. Living in a post-traditional society. In Reflexive Modernization: Politics, Tradition and Aesthetics in the Modern Social Order, U. Beck, A. Giddens \& S. Lash (eds), 56-109. Palo Alto CA: Stanford University Press

Hambye, P. \& Siroux, J.-L. 2008. Langage et "culture de la rue" en milieu scolaire. Sociologie et Sociétés 40 (2): 217-237. doi:10.7202/000672ar

Jaspers, J. 2011a. Interactional sociolinguistics and discourse analysis. In The Routledge Handbook of Discourse Analysis, J.P. Gee \& M. Handford (eds), 135-146. London: Routledge.

Jaspers, J. 2011b. Talking like a zero-lingual. Ambiguous linguistic caricatures at an urban secondary school. Journal of Pragmatics 43 (5): 1264-1278. doi:10.1016/j.pragma.2010.05.012

Jaspers, J. 2017, to appear. Language education policy and sociolinguistics. Toward a new critical engagement. In The Oxford Handbook of Language Policy and Planning, J. Tollefson \& M. Perez-Milans (eds). Oxford: OUP.

Jaspers, J. \& Madsen, L. M. 2016. Sociolinguistics in a languagised world: Introduction. Applied Linguistics Review 7 (3): 235-258.

Kermode, F. 2000. The Sense of an Ending. Oxford: OUP.

Kompridis, N. 2006. Critique and Disclosure. Critical Theory between Past and Future. Cambridge MA: The MIT Press.

Kramsch, C. 2015. Applied linguistics: A theory of the practice. Applied Linguistics 36 (4): 454-465. doi:10.1093/applin/amvo39

Lehtonen, H. 2016. Troping on prejudice: Stylised "bad Finnish" performances and reflexivity among adolescents in Eastern Helsinki. AILA Review 29 (1).

Lilis, T. 2015. Introduction. AILA Review 28: 1-6. doi:10.1075/aila.28.001int

Löwith, K. 1949. Meaning in History. The Theological Implications of the Philosophy of History. Chicago IL: University of Chicago Press.

Lu, L. 2016. Academically elite students in Singapore: A collective moral stance toward aspirations and trajectories. AILA Review 29 (1). 
McKnight, S. A. 1990. The legitimacy of the modern age: The Löwith-Blumenberg debate in light of recent scholarship. The Political Science Reviewer 19 (1): 177-195.

Marsh, J. 2011. Class Dismissed. New York NY: Monthly Review Press.

Moore, R. 2007. Sociology of Knowledge and Education. London: Continuum.

Parsons, T. 1937. The Structure of Social Action. New York NY: McGraw-Hill.

Patiño-Santos, A. 2016. Trapped in a moral order: Moral identity, positioning and reflexivity in stories of confrontation among Latin American teenage school girls in Madrid. AILA Review 29 (1).

Pérez-Milans, M. 2016. Reflexivity and social change in applied linguistics. AILA Review 29 (1). Pérez-Milans, M. \& Soto, C. 2016. Reflexive language and ethnic minority activism in Hong Kong: A trajectory-based analysis. AILA Review 29 (1).

Rampton, B. 2006. Language in Late Modernity. Interaction at an Urban School. Cambridge: CUP. doi:10.1017/CBO9780511486722

Reay, D. 2006. The zombie stalking English schools. Social class and educational Inequality. British Journal of Educational Studies 54 (3): 288-307. doi:10.1111/j.1467-8527.2006.00351.x

Reay, D. 2010. Sociology, social class and education. In The Routledge International Handbook of the Sociology of Education, M. W. Apple, S. J. Ball \& L. A. Gandin (eds), 396-404. London: Routledge.

Reay, D., Hollingworth, S., Williams, K., Crozier, G., Jamieson, F., James, D. \& Beedell, P. 2007. 'A darker shade of pale?' Whiteness, the middle classes and multi-ethnic inner city schooling. Sociology 41 (6): 1041-1060. doi:10.1177/0038038507082314

Reay, D., Crozier, G., James, D., Hollingworth, S., Williams, K., Jamieson, F. \& Beedell, P. 2008. Re-invigorating democracy? White middle class identities and comprehensive schooling. The Sociological Review 56 (2): 238-255. doi:10.1111/j.1467-954X.2008.00786.x

Silverstein, M. 1993. Metapragmatic discourse and metapragmatic function. In Reflexive Language. Reported Speech and Metapragmatics, J. A. Lucy (ed.), 33-58. Cambridge: CUP.

Skeggs, B. 2004. Class, Self, Culture. London: Routledge.

Talmy, S. 2009. Forever FOB? Resisting and reproducing the other in High School ESL. In Beyond Yellow English: Toward a Linguistic Anthropology of Asian Pacific America, A. Reyes \& A. Lo (eds), 347-365. Oxford: OUP. doi:10.1093/acprof:oso/9780195327359.003.0021

Van Lancker, I. 2016. The reflexive imperative among high-achieving adolescents: A Flemish case study. AILA Review 29 (1). 